\title{
Adsorption of Sulfur Dioxide on Clinoptilolite/Nano Iron Oxide and Natural Clinoptilolite
}

\author{
Mina Mahmoodi Meimand (iD ${ }^{1}$, Neda Javid (iD ${ }^{2}$ and Mohammad Malakootian (iD) ${ }^{1,3,{ }^{*}}$ \\ ${ }^{1}$ Environmental Health Engineering Research Center, Kerman University of Medical Sciences, Kerman, Iran \\ ${ }^{2}$ Department of Environmental Health Engineering, School of Public Health, Bam University of Medical Sciences, Bam, Iran \\ ${ }^{3}$ Department of Environmental Health, School of Public Health, Kerman University of Medical Sciences, Kerman, Iran \\ "Corresponding author: Environmental Health Engineering Research Center Kerman University of Medical Sciences, Haftbagh Highway, Kerman, Iran. Tel: +98-3431325128. Fax: \\ +98-3431325128, Email: m.malakootian@yahoo.com
}

Received 2018 April 07; Revised 2018 June 30; Accepted 2018 July 09.

\begin{abstract}
Background: Sulfur dioxide gas is known to include pollutants that are harmful to human health and the environment. Therefore, due to the increase of industrial activities, $\mathrm{SO}_{2}$ gas pollution control is very important.

Objectives: The purpose of this study was to investigate the efficiency of sulfur dioxide removal by iron oxide nanoparticles deposited on clinoptilolite zeolite.

Methods: Two materials, natural clinoptilolite and clinoptilolite containing iron oxide nanoparticles, were used as adsorbents of $\mathrm{SO}_{2}$. Both materials were characterized via scanning electron microscopy imaging, infrared spectroscopy, and $\mathrm{N}_{2}$ porosimetry, along with the determination of the thermodynamic properties and kinetics of $\mathrm{SO}_{2}$ adsorption. Therefore, breakthrough experiments were carried out at different temperatures and with different contact times. Sulfur dioxide adsorption of a real sample was considered for both adsorbents.

Results: The adsorption efficiency of $\mathrm{SO}_{2}$ in the synthetic and actual sample was obtained at $80.3 \%$ and $66.7 \%$, respectively, under optimum conditions (temperature of $25^{\circ} \mathrm{C}$ and duration of 28.5 minutes) by modified zeolite with iron oxide nanoparticles. The removal percentage average of $\mathrm{SO}_{2}$ was also obtained in the synthetic and actual sample at $43.8 \%$ and $31.3 \%$, respectively, by zeolite in optimum conditions (temperature of $25^{\circ} \mathrm{C}$ and contact time of 20.5 minutes). The adsorption of $\mathrm{SO}_{2}$ with both adsorbents followed the pseudo-second-order equation and the adsorption process was an exothermic and spontaneous process.
\end{abstract}

Conclusions: The addition of these iron oxide nanoparticles had a positive impact on the surface area and on $\mathrm{SO}_{2}$ capacity.

Keywords: Cardiovascular Diseases, Clinoptilolite, Environmental Pollution, Industry, Nanoparticles

\section{Background}

Sulfur dioxide is a non-flammable, non-explosive, and colorless gas that causes a taste in concentrations of 0.3 to $1 \mathrm{mg} / \mathrm{L}$ in the air. It has a strong, irritating odor in high concentrations of $3 \mathrm{mg} / \mathrm{L}(1) . \mathrm{SO}_{2}$ is turned in the atmosphere into more stable end-products (2). Sulfur dioxide is emitted into the atmosphere from the combustion of sulfurcontaining fossil fuels and industrial activities $(3,4)$.

$\mathrm{SO}_{2}$ emissions have adverse effects on human health such as respiratory problems and lung diseases $(5,6) . \mathrm{SO}_{2}$ can also have environmental consequences such as acid rain, which causes an increase in the acidity of lakes and rivers, the acidification of soils, damage to tree foliage and agricultural crops, and the corrosion of buildings and monuments (7).

Various technologies such as wet scrubbing or dry sorption methods have been developed for the removal of sulfur dioxide $(4,8)$. Because of their simplicity and relatively low cost, dry sorption methods are more economical than wet technologies (4). The adsorption process is a suitable method for the removal of pollutants from gaseous and aqueous environments (9-11). Dry processes, including the physical adsorption process, can be a promising strategy to remove $\mathrm{SO}_{2}$ due to its unique benefits such as low energy consumption for the adsorbent regeneration, relatively simple adsorbent design compared to the design of a chemical reactor, and few problems in waste disposal (12).

Many different adsorbents including activated carbon, alumina, graphite, rice husk ash, metal surfaces, and natural and synthetic zeolites have been applied for $\mathrm{SO}_{2}$ removal (13-19). Luo et al. reported that single gas adsorption results show that zeolite is more effective for $\mathrm{SO}_{2}, \mathrm{NO}$, and $\mathrm{CO}_{2}$ removal among the four adsorbents (20). Due to its abundance and low cost, clinoptilolite has been used of- 
ten in adsorption (21). Ivanova and Koumanova studied the modification of natural clinoptilolite from Bulgaria with salt solutions and examined the samples obtained for $\mathrm{SO}_{2}$ adsorption (22). Erdogan Alver found that the $\mathrm{SO}_{2}$ adsorption capacities of the clinoptilolite samples were superior to those of the $\mathrm{C}_{2} \mathrm{H}_{4}$ adsorptions (4).

Iron oxide is also common in the desulfurization process due to economic considerations and optimized dynamic properties (23). The use of nanosized iron oxide increases the efficiency of $\mathrm{SO}_{2}$ uptake due to an increased ratio of surface area to volume, it gets also properties which don't exist in macroscopic size (24). Abbasi et al. used $\mathrm{TiO}_{2}$ nanoparticles in the removal and sensing of $\mathrm{SO}_{2}$ (25). Arcibar-Orozco et al. found that iron nanoparticles of about $3-4 \mathrm{~nm}$ enhanced the $\mathrm{SO}_{2}$ adsorption capacity by about $80 \%$ by providing well-dispersed reactive centers (26).

\section{Objectives}

The purpose of this study was to investigate the efficiency of sulfur dioxide removal by iron oxide nanoparticles deposited on clinoptilolite zeolite.

\section{Methods}

\subsection{Preparation of the Adsorbent}

Clinoptilolite zeolite was purchased from the Afrazand Company. It was in the form of granulated natural clinoptilolite with an average diameter of 1 - $2 \mathrm{~mm}$. Ten grams of iron oxide nanoparticles (purity 99.5\%) was added to one liter of distilled water containing Erlenmeyer and suspended by an ultrasonic device as a homogenous suspension. The iron oxide nanoparticle suspension was added to $200 \mathrm{~g}$ of granulated zeolite and placed in a shaker for 2 hours, then slowly dried in an oven at $80^{\circ} \mathrm{C}$ for 10 hours. Finally, for the activation of the nanoparticles, a composite of iron oxide nanoparticles supported on clinoptilolite was heated in the oven at $300^{\circ} \mathrm{C}$ for 2 hours (27).

\subsection{Characterization of the Adsorbent}

Scanning electron microscopy (SEM) was used to determine the surface morphology of the prepared samples (28). It was taken in a model 30 scanning electron microscope manufactured by XL Philips. The Fourier-transform infrared spectroscopy (FT-IR) was used to investigate the chemical bonds and functional groups attached to the zeolite surface (29). FT-IR was performed with the spectrum GX model apparatus, made in America. The specific surface area of the adsorbent was determined by the BET (Brunauer - Emmet - Teller) method using a BELSORP-max (Bel Japan, Inc.) instrument (30).

\subsection{Adsorption Evaluation of $\mathrm{SO} 2$}

A glass cylinder with $19.5 \mathrm{~mm}$ diameter and $500 \mathrm{~mm}$ length was used for the experiment. One hundred grams of zeolite grains with nanoparticles and without nanoparticles was placed in the glass cylinder, separately. The sulfur dioxide gas was provided in a high-pressure cylinder, which contained 2700 ppm (purity 99.98\%) of $\mathrm{SO}_{2}$ balanced with $\mathrm{N}_{2}$. The gas cylinder was equipped with a pressure regulator. By passing a gas containing $\mathrm{SO}_{2}$, its removal rate was measured by determining the output concentration. The schematic diagram of the experimental setup is shown in Figure 1.

The gas flow rate was $1200 \mathrm{~mL} / \mathrm{min}$. Sampling was conducted during current to flow at 17, 20.5, 28.5, and 40 minutes and at $25,35,60$, and $80^{\circ} \mathrm{C}$. The required temperature was supplied using a 250 -watt electric heating element, which was wrapped around the chamber covering the cylinder. In order to set the exact temperature, the chamber's temperature was continuously controlled by a sensor, which was placed inside the chamber. The sensor acted quickly when the temperature was changed. If the chamber temperature was reduced from the desired temperature, the electronic thermostat quickly turned the heater on and if it was increased from the considered temperature, the thermostat turned the heater off.

After passing through the adsorbent, the gas entered in the Midget Impinger and was passed through a solution containing $\mathrm{H}_{2} \mathrm{O}_{2}$ (3\% vol.), for determining the amount of sulfur dioxide in the effluent. Then, the formed $\mathrm{H}_{2} \mathrm{SO}_{4}$ was measured by titrating with a $\mathrm{NaOH}(0.01 \mathrm{~mol} / \mathrm{L})$ solution and bromcresol green and methyl red as an indicator to determine the titration endpoint. The amount of $\mathrm{H}_{2} \mathrm{SO}_{4}$ was applied to calculate the total sulfur amount on the adsorbent (28). The amount of sulfur dioxide in the output current was determined according to the mentioned methods in the book of Standard Methods for the Examination of Water and Wastewater (APHA) (31).

The removal efficiency was calculated based on the reactor input and output concentration difference (Equation $1)$.

$$
\begin{aligned}
& \text { Removal Efficiency }(\%) \\
& =\frac{\text { Input } \mathrm{SO}_{2} \text { concentration }- \text { output } \mathrm{SO}_{2} \text { concentration }}{\text { Input } \mathrm{SO}_{2} \text { concentration }}
\end{aligned}
$$

Each experiment was performed three times. The exhaust outlet of a diesel automobile was used as a real sample.

\subsection{Instrumentation}

In this study, the instruments used included the HR200 analytical sensitive scale (A \& D, Japan) with precision of 


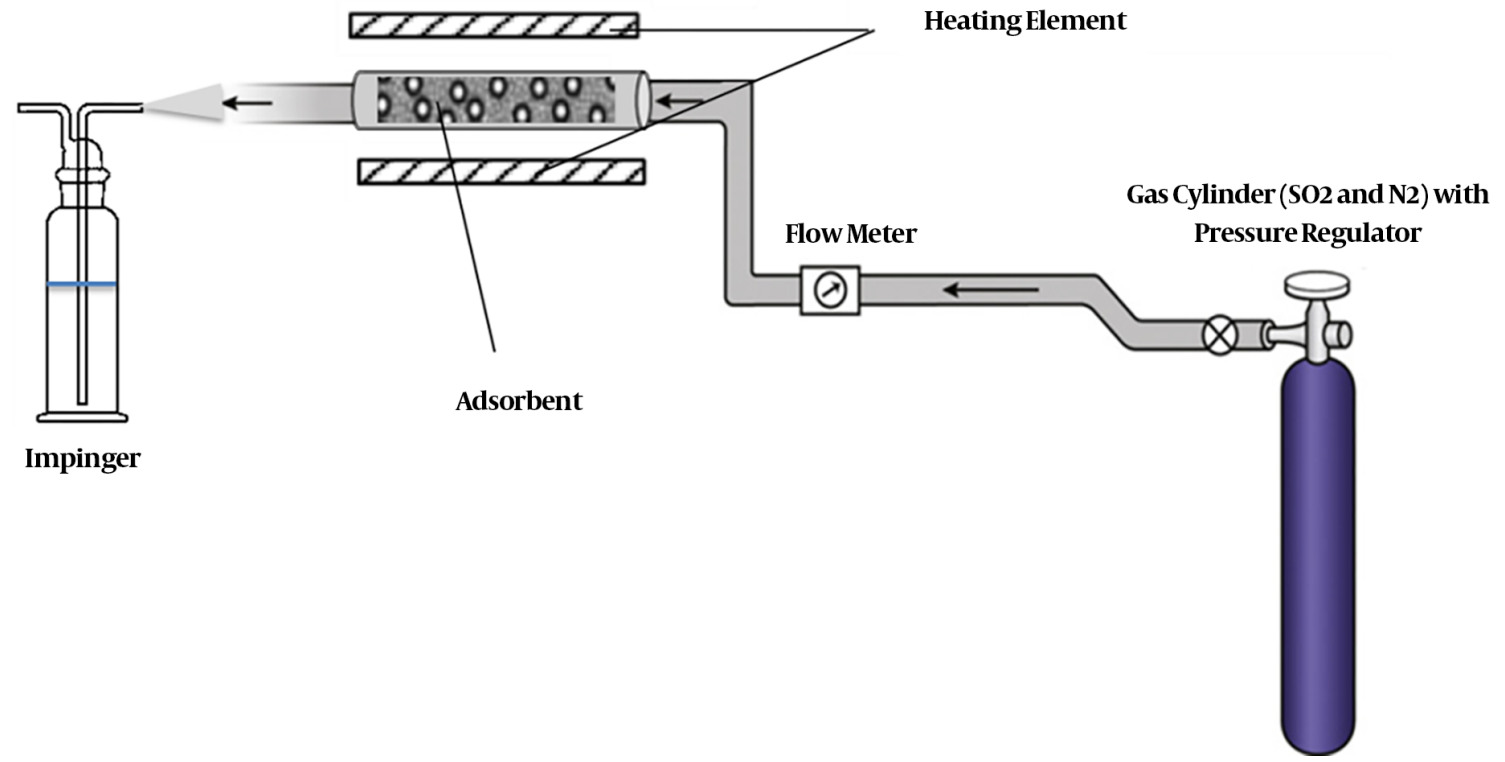

Figure 1. The schematic diagram of the experimental system

$0.0001 \mathrm{~g}$ for weighing chemicals, ultrasonic device TI-H5 model (Elma, Germany) for separating nanoparticles, water distillation device (Iran), shaker (Pars Azma company) for stirring, oven (Memmert, Germany) to heat and dry adsorbents, and the Taiwanese vacuum pump model of VC701. The chemicals that were used for the laboratory work were from Merck, Germany with high purity.

Data analysis was performed by descriptive statistics using the SPSS software (version 21).

\subsection{Adsorption Kinetics}

Kinetic models of pseudo-first-order and pseudosecond-order, respectively, were calculated using linear Equations 2 and 3 (32):

$\ln \left(q_{e}-q_{t}\right)=\ln q_{e}-K_{1} \times t$

$\frac{t}{q_{t}}=\frac{1}{k_{2} q_{e}^{2}}+\frac{1}{q_{e}} \times t$

Where $\mathrm{q}_{\mathrm{e}}$ is the amount of $\mathrm{SO}_{2}$ adsorbed at equilibrium $(\mathrm{mg} / \mathrm{g}), \mathrm{q}_{\mathrm{t}}$ is the amount of $\mathrm{SO}_{2}$ adsorbed at time $\mathrm{t}$ $(\mathrm{mg} / \mathrm{g})$, and $\mathrm{K}_{1}$ and $\mathrm{K}_{2}$ are the rate constants of these two equations (33). The diagram of $\log \left(\mathrm{q}_{\mathrm{e}}-\mathrm{q}_{\mathrm{t}}\right)$ against time and the diagram of $\mathrm{t} / \mathrm{q}_{\mathrm{t}}$ versus time was plotted to examine the pseudo-first-order and pseudo-second-order, respectively, for zeolite with and without the nanoparticles at $25^{\circ} \mathrm{C}$. The kinetic constants were obtained for both models by the determination of slope and intercept.

\subsection{Thermodynamic Properties of Adsorption}

To determine the thermodynamic parameters such as changes in standard Gibbs free energy $\left(\Delta G^{\circ}\right)$, standard enthalpy $\left(\Delta H^{\circ}\right)$, and standard entropy $\left(\Delta S^{\circ}\right)$, Equations 4 and 5 were employed (34):

$$
\begin{aligned}
& \ln K=\frac{\Delta S}{R}-\frac{\Delta H}{R T} \\
& \Delta G=\Delta H-T \Delta S
\end{aligned}
$$

So that a straight line is achieved by plotting changes of $\ln \mathrm{K}$ against 1/T. $\Delta \mathrm{H}^{\circ}$ and $\Delta \mathrm{S}^{\circ}$ obtained from the slope and intercept, respectively, of the linear plot.

\section{Results}

\subsection{Characterization of Natural and Modified Zeolite}

Natural and modified zeolite FTIR spectrums are shown in Figure 2A and B.

The SEM images of the natural clinoptilolite zeolite and clinoptilolite modified with iron oxide nanoparticles are illustrated in Figure $3 \mathrm{~A}$ and $\mathrm{B}$.

The BET surface area of natural clinoptilolite zeolite and modified zeolite with iron oxide nanoparticles were obtained at $19.44 \mathrm{~m}^{2} / \mathrm{g}$ and $21.7 \mathrm{~m}^{2} / \mathrm{g}$, respectively. Adding nanoparticles of iron oxide as the active phase on the clinoptilolite zeolite has increased the specific surface area. The contact surface increases due to the small size of nanoparticles. 
A

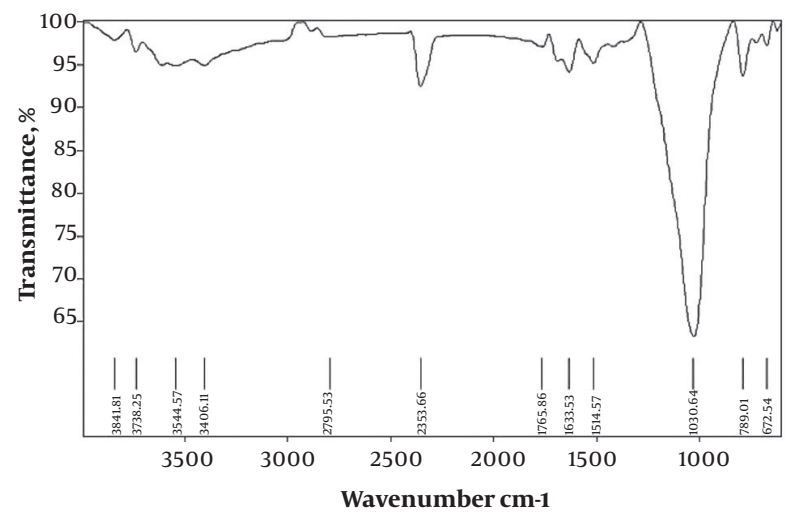

B

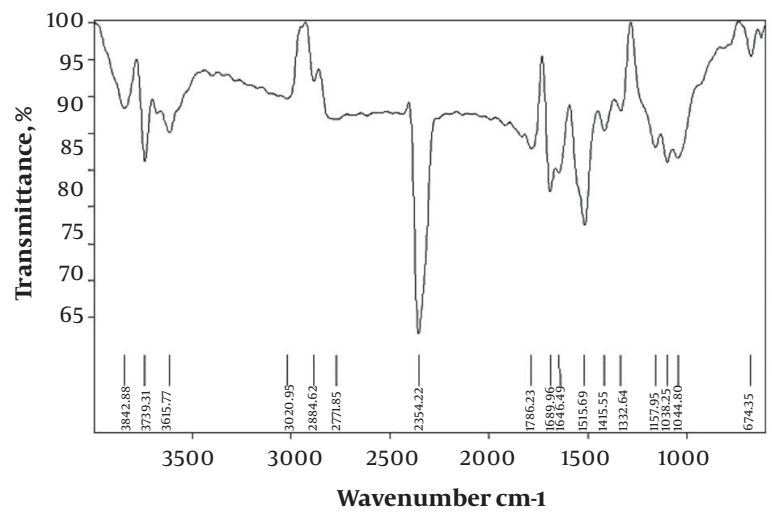

Figure 2. FTIR spectrums of (A) natural zeolite and (B) zeolite modified with iron oxide nanoparticles
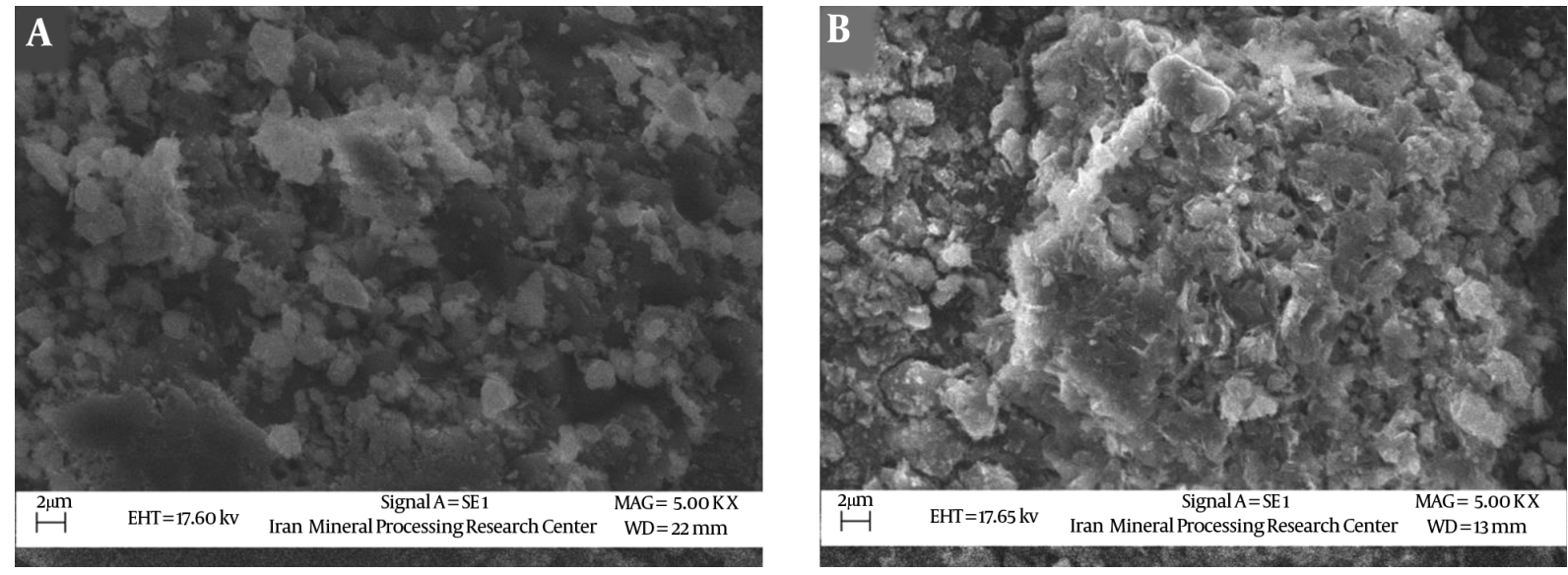

Figure 3. SEM images of natural clinoptilolite (A) and clinoptilolite modified with nanoparticles and (B) 5000-times magnification

\subsection{Effect of Temperature}

The results of the effect of temperature on the removal of sulfur dioxide in natural and modified zeolite are presented in Figure 4.

The maximum values of $\mathrm{SO}_{2}$ removal efficiency is at a temperature of $25^{\circ} \mathrm{C}$ by natural and modified zeolite are $43.8 \%$ and $80.3 \%$, respectively.

\subsection{Effect of Contact Time}

The influence of contact time on the $\mathrm{SO}_{2}$ removal efficiency was investigated and the results are provided in Figure 5.

The maximum removal efficiency of $\mathrm{SO}_{2}$ obtained in the contact time of 20.5 minutes by natural zeolite at $43.8 \%$.

Also, the maximum removal capacity of $\mathrm{SO}_{2}$ obtained in the contact time of $\mathbf{2 8 . 5}$ minutes for modified zeolite at $80.3 \%$.

\subsection{Adsorption Kinetics}

The values of $\mathrm{K}_{1}, \mathrm{~K}_{2}$, and $\mathrm{q}_{\mathrm{e}}$ are presented in Table 1 along with the corresponding correlation coefficients $\left(\mathrm{R}^{2}\right)$.

It can be seen from Table 1 that the adsorption of $\mathrm{SO}_{2}$ on the natural zeolite and the modified zeolite with nanoparticles follows the pseudo-second-order kinetic model because the linearity percent of this equation is more than the other equation.

\subsection{Adsorption Thermodynamics}

The thermodynamic parameters including changes in standard Gibbs free energy $\left(\Delta G^{\circ}\right)$, standard enthalpy $\left(\Delta \mathrm{H}^{\circ}\right)$, and standard entropy $\left(\Delta \mathrm{S}^{\circ}\right)$ were calculated from the variation of the thermodynamic equilibrium constant, $\mathrm{K}$, at different temperatures (34). Values $\Delta \mathrm{H}^{\circ}, \Delta \mathrm{S}^{\circ}$, and $\Delta \mathrm{G}^{\circ}$ of the adsorption process are listed in Table 2. 


\begin{tabular}{|c|c|c|c|c|c|c|}
\hline \multirow{2}{*}{ Adsorbent } & \multicolumn{3}{|c|}{ Pseudo-First-Order Kinetic Model } & \multicolumn{3}{|c|}{ Pseudo-Second-Order Kinetic Model } \\
\hline & $\mathbf{K}_{\mathbf{1}}$ & $\mathbf{q}_{\mathrm{e}}(\mathrm{mg} / \mathrm{g})$ & $\mathbf{R}^{2}$ & $\mathbf{K}_{\mathbf{2}}$ & $q_{e}(\mathrm{mg} / \mathrm{g})$ & $\mathbf{R}^{2}$ \\
\hline Natural clinoptilolite zeolite & 0.154 & 70.1 & 0.6786 & 0.015 & 8.3 & 0.9931 \\
\hline $\begin{array}{l}\text { Modified zeolite with } \\
\text { nanoparticles }\end{array}$ & 0.182 & 365 & 0.9096 & 0.014 & 21.9 & 0.9942 \\
\hline \multirow[t]{2}{*}{ Temperature (K) } & \multicolumn{3}{|c|}{ Natural Clinoptilolite Zeolite } & \multicolumn{3}{|c|}{ Modified Zeolite with Nanoparticles } \\
\hline & $\Delta \mathbf{G}^{\circ}(\mathrm{J})$ & $\Delta S^{\circ}(\mathrm{J} / \mathbf{m o l})$ & $\Delta \mathbf{H}^{\circ}(\mathrm{J} / \mathbf{m o l})$ & $\Delta \mathbf{G}^{\circ}(\mathrm{J})$ & $\Delta S^{\circ}(\mathrm{J} / \mathbf{m o l})$ & $\Delta \mathbf{H}^{\circ}(\mathrm{J} / \mathbf{m o l})$ \\
\hline 298 & -5476 & 2.3 & -4791 & -9622 & -20.2 & -15642 \\
\hline 308 & -5499 & & & -9420 & & \\
\hline 333 & -5557 & & & -8915 & & \\
\hline 353 & -5603 & & & -8511 & & \\
\hline
\end{tabular}

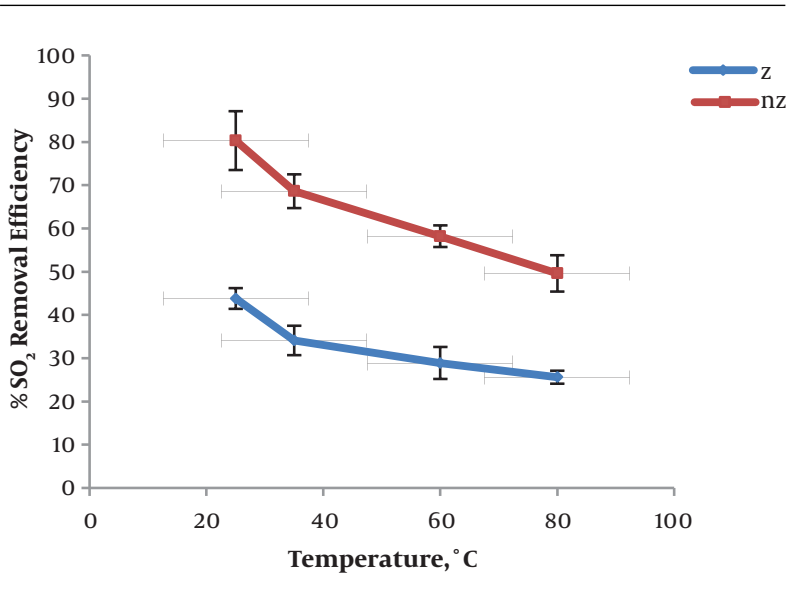

Figure 4. The influence of temperature on the removal efficiency of sulfur dioxide

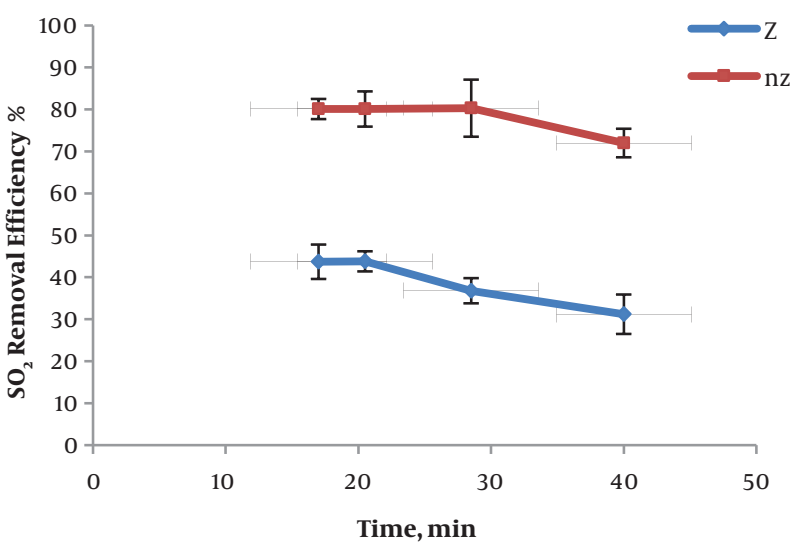

Figure 5. The influence of contact time on the removal efficiency of sulfur dioxide
It can be seen from Table 2 that Gibbs free energy has negative values at all temperatures. The negative values of $\Delta \mathrm{G}^{\circ}$ indicate that the adsorption process of $\mathrm{SO}_{2}$ is spontaneous. The negative value of $\Delta S^{\circ}$ in this table demonstrates a decreased degree of disorderliness during the adsorption of $\mathrm{SO}_{2}$ onto modified zeolite with nanoparticles. But $\Delta S^{\circ}$ is positive for natural clinoptilolite zeolite, which represents an increased degree of irregularity during the adsorption process. The negative value of $\Delta \mathrm{H}^{\circ}$ confirms that the adsorption of $\mathrm{SO}_{2}$ is exothermic $(35,36)$.

\subsection{Adsorption of Real Sample}

Sulfur dioxide gas was used alone for the laboratory and synthetic sample, but to check the efficiency of the method in real conditions in the presence of other intervening factors, the diesel exhaust was used. The results showed that the efficiency of this method in actual conditions and in the presence of other intervening factors is $13.6 \%$ and $12.5 \%$ less than the laboratory sample. The removal rate obtained was $66.7 \%$ and $31.3 \%$ by modified zeolite with iron oxide nanoparticles and natural zeolite, respectively, which indicates the efficiency of this method in real terms.

\section{Discussion}

In the FT-IR spectra of the amended zeolite with nanoparticles, vibrations of the hydroxyl functional group bands at $3615 \mathrm{~cm}^{-1}$ can be seen. The peak at $1689 \mathrm{~cm}^{-1}$ is associated with vibrations in the Si-O band. Also, the peaks at $1515 \mathrm{~cm}^{-1}, 1415 \mathrm{~cm}^{-1}$, and $789 \mathrm{~cm}^{-1}$ are due to Fe-O bands that appeared after the functionalization (37).

The SEM image of the natural clinoptilolite zeolite shows that the structure distribution of the zeolite is in 
an irregular form. In addition, the modifying zeolite with nanoparticles has increasing levels of zeolite. Images of the surface of the blended zeolite with nanoparticles also demonstrate the surface of zeolite is covered with iron oxide nanoparticles.

The results of the BET surface area indicate that the modification of natural zeolite by nanoparticles has caused an enhancement of the zeolite specific surface area, which is due to the small size of the nanoparticles, thus, increasing the contact area.

The results of the investigation of temperature indicate that the removal efficiency of sulfur dioxide is reduced with increasing temperature. It is well understood that physical adsorption decreases with increasing temperature according to Le Chatelier's Principle. Increasing temperature enhances the movement speed of the particles and causes desorption, which can decrease the removal efficiency. Al-Harahsheh et al. studied the removal of $\mathrm{SO}_{2}$ by natural zeolite. They found that the $\mathrm{SO}_{2}$ adsorption process is exothermic on the zeolite (38). Zhou et al. studied sulfur dioxide adsorption on activated carbon. They reported that the adsorption decreases with increasing temperature and $\Delta \mathrm{H}^{\circ}$ is a negative value, which complies with the result of this study (39). Vhdat Parast et al. found that by increasing the temperature, xylene adsorption on clinoptilolite is declined (40).

The results of the investigation of the contact time demonstrate that most of the adsorption process occurs during the contact time of 20.5 and 28.5 minutes for natural zeolite and modified zeolite, respectively. By increasing the contact time, the adsorption efficiency decreases due to the restricted surface area available for adsorption. In the adsorption process, molecules physically adsorb to the adsorbent and separate from the gas stream. When all the pores of the adsorbent are filled, it is unable to adsorb more contaminant (41). Zhang et al. found that with increasing contact time, the $\mathrm{SO}_{2}$ removal efficiency by $\mathrm{CaO}$ as desulfurizers decreased; this is similar to the results of the current study (42). In another study by Mofidi et al. also, the removal efficiency of activated carbon for VOCs adsorption declined after a certain time (99 min) (41). Bahiraei et al. investigated the adsorption performance of $\gamma-\mathrm{Fe}_{2} \mathrm{O}_{3}$ nanoparticles for sulfide, sulfite, and thiosulfate from aqueous solutions. They reported that the adsorption process followed pseudo-second-order kinetics, which is similar with results of this study (43).

Various biological, adsorption, and catalytic procedures are used to remove pollutants from the air. These methods demonstrate the premier adsorption properties of natural zeolites such as modified clinoptilolite. Since the catalytic properties of the zeolite are not strong enough it is considered more for their adsorbing proper- ties (44). Malakootian et al. found that the efficiency of natural and modified zeolite is relatively high in the adsorption of antibiotic tetracycline (45). On the other hand, studies have shown the catalytic properties of transition metals nanoparticles such as iron and copper in the removal of air pollutants (46). Sekhavatjou et al. investigated the removal of sulfur components from sour gas through the application of zinc and iron oxides nanoparticles (24). Also, the study by Li et al. have shown the catalytic and oxidant properties of iron nanoparticles for carbon monoxide. In their study, the conversion of carbon monoxide to carbon dioxide by $90 \%$ at $230^{\circ} \mathrm{C}$ was observed (27). Therefore, in the present study, the mechanisms of adsorption and catalysis can affect the efficiency of the removal of the $\mathrm{SO}_{2}$ adsorbing properties of zeolite and the strong catalytic activity of iron oxide nanoparticles. Liu et al. found that Fe additions on activated carbon showed higher $\mathrm{SO}_{2}$ adsorption capacity than the original activated carbon (28). Shen et al. investigated the removal of heavy metals by iron oxide nanoparticles. They found that the removal rate of these ions was higher using nanoparticles than a sample without nanoparticles. In addition to the iron oxide nanoparticles being very small in size, they also cover a very large surface area. Also, the functional groups on iron oxide nanoparticles increase the number of reactions. Finally, these two issues justify the high adsorption capacity of nanoparticles (47).

\subsection{Conclusions}

According to results, a modified zeolite with iron oxide nanoparticles has a better efficiency in adsorbing sulfur dioxide compared to unmodified zeolite due to iron oxide nanoparticles being regenerative. It can be considered as a practical, reliable, and efficient method for the removal of sulfur dioxide from the air.

\section{Acknowledgments}

This research was conducted at the Environmental Health Engineering Research Center and was sponsored by the vice chancellor for research and technology of the Kerman University of Medical Sciences. The authors' appreciation is expressed here to the vice chancellor and to all university staff who provided assistance to make this study possible.

\section{Footnotes}

Authors' Contribution: All authors contributed equally and participated in the collection, analysis, and interpretation of the data. All authors critically reviewed, refined, and approved the manuscript. 
Conflict of Interests: It is not declared by the author.

Ethical Approval: 94-287.

Funding/Support: This research was conducted at the Environmental Health Engineering Research Center and was sponsored by the vice chancellor for research and technology of the Kerman University of Medical Sciences.

\section{References}

1. Wark K, Warner CF. Air pollution: Its origin and control.1981.

2. Song XD, Wang S, Hao C, Qiu JS. Investigation of $\mathrm{SO} 2$ gas adsorption in metal-organic frameworks by molecular simulation. Inorg Chem Comm. 2014;46:277-81. doi: 10.1016/j.inoche.2014.06.003.

3. Liu Z, Mao X, Tu J, Jaccard M. A comparative assessment of economicincentive and command-and-control instruments for air pollution and $\mathrm{CO} 2$ control in China's iron and steel sector. J Environ Manage. 2014;144:135-42. doi: 10.1016/j.jenvman.2014.05.031. [PubMed: 24945700].

4. Erdogan Alver B. A comparative adsorption study of $\mathrm{C} 2 \mathrm{H} 4$ and SO2 on clinoptilolite-rich tuff: Effect of acid treatment. J Hazard Mater. 2013;262:627-33. doi: 10.1016/j.jhazmat.2013.09.014. [PubMed: 24100260].

5. Girard JE, Girard J. Principles of environmental chemistry. Jones \& Bartlett Publishers; 2013.

6. Geravandi S, Goudarzi G, Mohammadi MI, Taghavirad SS, Salmanzadeh $S$. Sulfur and nitrogen dioxide exposure and the incidence of health endpoints in Ahvaz, Iran. Health Scope. 2015;4(2). doi: 10.17795/jhealthscope-24318.

7. Nagase Y, Silva ECD. Acid rain in China and Japan: A gametheoretic analysis. Reg Sci Urban Econ. 2007;37(1):100-20. doi: 10.1016/j.regsciurbeco.2006.08.001.

8. Savage M, Cheng Y, Easun TL, Eyley JE, Argent SP, Warren MR, et al. Selective adsorption of sulfur dioxide in a robust metalorganic framework material. Adv Mater. 2016;28(39):8705-11. doi 10.1002/adma.201602338. [PubMed: 27529671].

9. Malakootian M, Jafarzadeh Haghighifard N, Moussavi G, Hossaini $\mathrm{H}$. Investigation of ammonium ion adsorption onto regenerated spent bleaching earth: Parameters and equilibrium study. Environ Eng ManagJ (EEMJ). 2016;15(4).

10. Malakootian M, Jafari Mansoorian H, Hosseini A, Khanjani N. Evaluating the efficacy of alumina/carbon nanotube hybrid adsorbents in removing Azo Reactive Red 198 and Blue 19 dyes from aqueous solutions. Process Saf Environ Protect. 2015;96:125-37. doi: 10.1016/j.psep.2015.05.002.

11. Malakootian M, Mohammadi S, Amirmahani N, Nasiri Z, Nasiri A. Kinetics, thermodynamics and equilibrium studies on adsorption of Reactive Red 198 from textile wastewater by coral limestone as a natural sorbent. J Community Health Res. 2016;5(2):73-89.

12. Gollakota SV, Chriswell CD. Study of an adsorption process using silicalite for sulfur dioxide removal from combustion gases. Ind Eng Chem Res. 1988;27(1):139-43. doi: 10.1021/ie00073a025.

13. Rao SNR, Waddell E, Mitchell MB, White MG. Selective sulfur dioxide adsorbents prepared from designed dispersions of groups IA and IIA metal oxides on alumina. J Catal. 1996;163(1):176-85. doi: 10.1006/jcat.1996.0317.

14. Seredych M, Bandosz TJ. Effects of surface features on adsorption of $\mathrm{SO} 2$ on graphite oxide $/ \mathrm{Zr}(\mathrm{OH}) 4$ composites. J Phys Chem C. 2010;114(34):14552-60. doi:10.1021/jp1051479.

15. Dahlan I, Mei GM, Kamaruddin AH, Mohamed AR, Lee KT. Removal of SO2 and NO over rice husk ash (RHA)/CaO-supported metal oxides. J Eng Sci Tech. 2008;3(2):109-16.
16. Li G, Wang Q, Jiang T, Luo J, Rao M, Peng Z. Roll-up effect of sulfur dioxide adsorption on zeolites FAU 13X and LTA 5A. Adsorption. 2017;23(5):699-710. doi: 10.1007/s10450-017-9887-0.

17. Rosas JM, Ruiz-Rosas R, Rodriguez-Mirasol J, Cordero T. Kinetic study of $\mathrm{SO} 2$ removal over lignin-based activated carbon. Chem Eng J. 2017;307:707-21. doi: 10.1016/j.cej.2016.08.111.

18. Chen Y, Huang B, Huang M, Lu Q, Huang B. Sticky rice lime mortarinspired in situ sustainable design of novel calcium-rich activated carbon monoliths for efficient SO2 capture.J Clean Prod. 2018;183:44957. doi: 10.1016/j.jclepro.2018.02.167.

19. Shokuhi Rad A, Chourani A. Nickel based paddle-wheel metal-organic frameworks towards adsorption of $\mathrm{O} 3$ and $\mathrm{SO} 2$ molecules: Quantum-chemical calculations. J Inorg Organomet Polymer Mater. 2017;27(6):1826-34. doi: 10.1007/s10904-017-0648-Z.

20. Luo L, Guo Y, Zhu T, Zheng Y. Adsorption species distribution and multicomponent adsorption mechanism of $\mathrm{SO} 2, \mathrm{NO}$, and $\mathrm{CO} 2$ on commercial adsorbents. Energ Fuel. 2017;31(10):11026-33. doi: 10.1021/acs.energyfuels.7b01422.

21. Allen SJ, Ivanova E, Koumanova B. Adsorption of sulfur dioxide on chemically modified natural clinoptilolite. Acid modification. Chem EngJ.2009;152(2-3):389-95. doi: 10.1016/j.cej.2009.04.063.

22. Ivanova E, Koumanova B. Adsorption of sulfur dioxide on natural clinoptilolite chemically modified with salt solutions. $J \mathrm{Haz}$ ard Mater. 2009;167(1-3):306-12. doi: 10.1016/j.jhazmat.2008.12.124. [PubMed: 19200655].

23. Tomas-Alonso F, Palacios Latasa JM. Synthesis and surface properties of zinc ferrite species in supported sorbents for coal gas desulphurisation. Fuel Process Tech. 2004;86(2):191-203. doi: 10.1016/j.fuproc.2004.03.004.

24. Sekhavatjou M, Moradi R, Hosseini Alhashemi A, Taghinia Hejabi A. A new method for sulfur components removal from sour gas through application of zinc and iron oxides nanoparticles. Int J Environ Res. 2014;8(2):273-8. doi: 10.22059/ijer.2014.716.

25. Abbasi A, Sardroodi JJ, Ebrahimzade AR. The adsorption of $\mathrm{SO} 2$ on $\mathrm{TiO} 2$ anatase nanoparticles: A density functional theory study. Can J Chem. 2015;94(1):78-87. doi: 10.1139/cjc-2015-0065.

26. Arcibar-Orozco JA, Rangel-Mendez JR, Bandosz TJ. Reactive adsorption of $\mathrm{SO} 2$ on activated carbons with deposited iron nanoparticles.J Hazard Mater. 2013;246-247:300-9. doi: 10.1016/j.jhazmat.2012.12.001.

27. Li P, Miser DE, Rabiei S, Yadav RT, Hajaligol MR. The removal of carbon monoxide by iron oxide nanoparticles. Appl Catal B Environ. 2003;43(2):151-62. doi: 10.1016/s0926-3373(02)00297-7.

28. Liu XL, Guo IX, Chu YH, Luo DM, Yin HQ, Sun MC, et al. Desulfurization performance of iron supported on activated carbon. Fuel. 2014;123:93-100. doi: 10.1016/j.fuel.2014.01.068.

29. Garshasbi V, Jahangiri M, Anbia M. Equilibrium CO2 adsorption on zeolite 13X prepared from natural clays. Appl Surf Sci. 2017;393:225-33. doi: 10.1016/j.apsusc.2016.09.161.

30. Jesudoss SK, Vijaya JJ, Grace AA, Kennedy LJ, Sivasanker S, Kathirgamanathan P. Hierarchical ZSM-5 zeolite nanosurfaces with high porosity-structural, morphological and textural investigations. In: Ebenezar J, editor. Recent trends in materials science and applications. 189. Springer Proceedings in Physics; 2017. p. 109-18. doi: 10.1007/9783-319-44890-9_11.

31. American Public Health Association; American Water Works Association; Water Pollution Control Federation; Water Environment Federation. Standard methods for the examination of water and wastewater. 2. American Public Health Association; 1915.

32. Ho YS, McKay. G. The kinetics of sorption of divalent metal ions onto sphagnum moss peat. Water Res. 2000;34(3):735-42. doi: 10.1016/s0043-1354(99)00232-8.

33. Zhao C, Guo Y, Li W, Bu C, Wang X, Lu P. Experimental and modeling investigation on $\mathrm{CO} 2$ sorption kinetics over $\mathrm{K} 2 \mathrm{CO} 3$-modified silica aerogels. Chem EngJ. 2017;312:50-8. doi: 10.1016/j.cej.2016.11.121.

34. Chattaraj S, Mohanty D, Kumar T, Halder G. Thermodynamics, kinetics and modeling of sorption behaviour of coalbed 
methane - A review. J Unconvent Oil Gas Resource. 2016;16:14-33. doi:10.1016/j.juogr.2016.09.001.

35. Vega ED, Narda GE, Ferretti FH. Adsorption of citric acid from dilute aqueous solutions by hydroxyapatite. J Colloid Interface Sci. 2003;268(1):37-42. [PubMed: 14611769].

36. Sun L, Zhu X. Practical and theoretical study of the adsorption performances of straw-based tertiary amine-supported material toward sulfur dioxide in flue gas. Bioresources. 2017;13(1):1132-42. doi: 10.15376/biores.13.1.1132-1142.

37. Ruiz-Baltazar A, Esparza R, Gonzalez M, Rosas G, Perez R. Preparation and characterization of natural zeolite modified with iron nanoparticles. J Nanomater. 2015;16(1):247. doi: 10.1155/2015/364763.

38. Al-Harahsheh M, Shawabkeh R, Batiha M, Al-Harahsheh A, Al-Zboon K. Sulfur dioxide removal using natural zeolitic tuff. Fuel Process Tech. 2014;126:249-58. doi:10.1016/j.fuproc.2014.04.025.

39. Zhou X, Yi H, Tang X, Deng H, Liu H. Thermodynamics for the adsorption of $\mathrm{SO} 2, \mathrm{NO}$ and $\mathrm{CO} 2$ from flue gas on activated carbon fiber. Chem EngJ. 2012;200-202:399-404. doi:10.1016/j.cej.2012.06.013.

40. Vahdat Parast Z, Asilian H, Jonidi Jafari A. Adsorption of xylene from air by natural Iranian zeolite. Health Scope. 2014;3(3). doi: 10.17795/jhealthscope-17528.

41. Mofidi A, Asilian H, Jonidi Jafari A. Adsorption of volatile organic compounds on fluidized activated carbon bed. Health Scope. 2013;2(2):849. doi: 10.17795/jhealthscope-9833.
42. Zhang T, Li J, Yu S, Wang Y. Preparation and characterization of a new desulfurizer and its performance on removal of SO2.J Geosci Environ Protect. 2014;2(2):68-76. doi:10.4236/gep.2014.22011.

43. Bahiraei A, Afkhami A, Madrakian T, Gheitaran R. Preparation and characterization of $\gamma$ - $\mathrm{Fe} 2 \mathrm{O} 3$ nanoparticles and investigation of its adsorption performance for sulfide, sulfite and thiosulfate from aqueous solutions using ultrasonic assisted method: Modeling and optimization. Ultrason Sonochem. 2018;40:1049-58. doi 10.1016/j.ultsonch.2017.08.035.

44. Hernandez MA, Corona L, Gonzalez AI, Rojas F, Lara VH, Silva F. Quantitative study of the adsorption of aromatic hydrocarbons (benzene, toluene, and p-xylene) on dealuminated clinoptilolites. Ind Eng Chem Res. 2005;44(9):2908-16. doi:10.1021/ie049276w.

45. Malakootian M, Nori Sepehr M, Bahraini S, Zarrabi M. [Capacity of natural and modified zeolite with cationic surfactant in removal of antibiotic tetracycline from aqueous solutions]. Koomesh. 2016;17(3):779-88. Persian.

46. Henn KW, Waddill DW. Utilization of nanoscale zero-valent iron for source remediation-A case study. Remed J. 2006;16(2):57-77. doi: 10.1002/rem.20081.

47. Shen YF, Tang J, Nie ZH, Wang YD, Ren Y, Zuo L. Preparation and application of magnetic $\mathrm{Fe} 3 \mathrm{O} 4$ nanoparticles for wastewater purification. Separ Purif Tech. 2009;68(3):312-9. doi:10.1016/j.seppur.2009.05.020. 